\title{
Optimising risk reduction: an expected utility approach for marginal risk reduction during regulatory decision-making
}

\author{
Jiawei $\mathrm{Li}^{1 *}$, Simon Pollard ${ }^{2}$, Graham Kendall ${ }^{1}$, Emma Soane $^{3}$, Gareth Davies ${ }^{2}$ \\ ${ }^{1}$ School of Computer Science, University of Nottingham, Nottingham NG8 1BB \\ ${ }^{2}$ School of Applied Sciences, Cranfield University, Cranfield, MK43 0AL \\ ${ }^{3}$ Department of Management, London School of Economics, London, WC2A 2AE \\ * Corresponding author. Tel: +44 (0)115 8466535; Fax: +44 (0)115 9514249. \\ Email addresses: jwl@cs.nott.ac.uk (J. Li), s.pollard@cranfield.ac.uk (S. Pollard), \\ gxk@cs.nott.ac.uk (G. Kendall), E.C.Soane@lse.ac.uk (E. Soane), \\ g.davies@cranfield.ac.uk (G. Davies).
}

\begin{abstract}
In practice, risk and uncertainty are essentially unavoidable in many regulation processes. Regulators frequently face a risk-benefit trade-off since zero risk is neither practicable nor affordable. Although it is accepted that cost-benefit analysis is important in many scenarios of risk management, what role it should play in a decision process is still controversial. One criticism of cost-benefit analysis is that decision makers should consider marginal benefits and costs, not present ones, in their decision making. In this paper, we investigate the problem of regulatory decision making under risk by applying expected utility theory and present a new approach of cost-benefit analysis. Directly taking into consideration the reduction of the risks, this approach achieves marginal costbenefit analysis. By applying this approach, the optimal regulatory decision that maximizes the marginal benefit of risk reduction can be considered. This provides a transparent and reasonable criterion for stakeholders involved in the regulatory activity. An example of evaluating seismic retrofitting alternatives is provided to demonstrate the potential of the proposed approach.
\end{abstract}


Key words: Regulatory decision making, cost-benefit analysis, ALARP, expected utility theory

\section{INTRODUCTION}

One long-standing theme within regulatory risk management is evaluating the costbenefit of managing risk. Assuming a risk warrants active management, what is a reasonable spend on risk management; when does this spend become disproportionate to the benefits that a managed risk brings and how far should investment in risk management continue, if at all, beyond the point whereby the risk is deemed insignificant? In essence, this is an optimisation problem inherently bound up with the law of diminishing returns, in that continued investment in risk management results in ever-decreasing incremental reductions in risk of lesser incremental value. Wise risk managers understand that the principal benefits of risk reduction are likely to be secured by targeting resources at a relatively few features of a problem, and that this action will be optimised when the risk is reduced to that which is as low as reasonably practicable (ALARP) or achievable (ALARA). Thereafter, increased investment may become disproportionate to the benefits gained. ALARP and ALARA are well-researched concepts within health and safety legislation, radiation protection and to a limited extent within environmental protection. ALARP has been controversial and subject to several court rulings; especially with respect to what constitutes a reasonable expectation of investment by a regulated party, and thus the concept of gross disproportionality (of investment in risk management compared to the risk reduction benefits gained). A 
familiar regulatory discussion involves the regulator and regulated party exchanging views on (i) the initial significance of a risk, thus triggering a risk management action where the risk is deemed significant; followed by (ii) an enthusiastic debate on the practicalities and costs of risk management (often requiring additional investment), which may secures agreement over the residual risk level and degree of investment. What guidance can researchers bring to these debates?

Fig.1 illustrates the framework the HSE (Health and Safety Executive, UK) has adopted in its regulation process [1]. The inverted triangle represents an increasing level of risk for a particular hazardous activity as we move from the bottom of the triangle towards the top. The regulators' objective is twofold. Firstly to ensure that the risks do not exceed an unacceptable level, and secondly to ensure that risk management measures put in place to reduce risk are proportionate to the risk. Practically, the degree of risk often falls in the ALARP region, so that benefits are achieved while being prepared to tolerate the risks from the activities. This framework provides a reasonable description of regulatory decision making under risk. However, suppose there are several feasible solutions to an environmental problem, each of which leads to a degree of residual risk that falls into the ALARP region, for example. How the regulator should choose among these alternatives?

This is the field of options appraisal for risk reduction, of which an economic component is only one aspect. Cost-benefit analysis (CBA) was originally used to evaluate the desirability of governmental intervention in markets, and has now been used in many areas of public decision making. Typical fields of application include transportation $[2,3]$, health care $[4,5]$, environment [6-10], and safety [11, 12]. The 
essential foundations of cost-benefit analysis are: benefits and costs are narrowly defined as monetary values, and an activity is worthwhile only if its benefits exceed its costs. A benefit-cost ratio which is the ratio of total benefits relative to total costs is commonly used as one of the criteria in regulatory decision making. Some important issues on CBA have been widely investigated, for example, uncertainty $[13,14]$, discounting rates $[15-$ 17], and equity [18].

Most researchers agree that benefit-cost ratios are neither necessary nor sufficient for the regulatory decisions, partially because economic factors are usually not the most important, and partially because not all important factors for decision making can be quantified $[19,18]$. In some areas, the regulation of nuclear waste disposal for example, the optimisation of risk reduction in the ALARP region has received considerable attention.

One criticism of cost-benefit analysis is that decision makers should consider marginal benefits, not present ones, in decision making. Marginal benefit is the increase of total benefit as a result of an extra investment in risk reduction. This concept grew out of attempts by economists to explain the determination of price [20, 21]. It is often assumed in economics that as the amount of any one input is increased, holding all other inputs constant, the amount that output increases for each additional unit of the expanding input will generally decrease. This law of diminishing marginal utility implies that there exists an optimal amount of input such that the efficiency of the investment is maximized. The objective of marginal analysis then, is to find out the optimal solution among those alternatives of investment. Within the context of risk regulation, marginal benefit represents the marginal effect of risk reduction, mathematically the first derivative 
of the total benefit with respect to the amount of investment, from a range of alternatives. In most scenarios of risk regulation, the possibilities of disaster (risk) can only be reduced to some values above zero and further reduction will be unaffordable. Therefore, marginal analysis can contribute to the optimisation of risk reduction in the ALARP region. We have not found any application of marginal analysis in CBA. The reason might lie in the difficulty of connecting a reduction of risk with monetary values of benefit and cost, especially in the fields of health and safety and environmental legislation where externalities are prominent. Below, we propose an approach that maximizes the marginal benefit of risk reduction by estimating the first order condition of expected utility. With this approach, different alternatives can be compared according to their efficiencies in reducing risk with least monetary expenditure.

This approach could be a supplement to the framework of ALARP and quantified risk assessment. Applying ALARP requires a comparison of different credible risk reduction strategies in order to demonstrate at what level the risks are optimised. It is difficult to achieve it because we lack criteria on how efficient the risks could be reduced for each risk management option $[22,23]$. This approach is especially suitable for the comparisons of different risk reduction methods.

\section{AN EXPECTED UTILITY APPROACH OF COST-BENEFIT}

\section{ANALYSIS}

Expected utility theory has long been an approach to deal with the problem of decision making under risk and uncertainty in economics. The axiomatic hypothesis of expected utility is that the decision maker can make a possibility distribution over possible 
outcomes of activities. When applying expected utility theory to regulatory decision making, we need to assume that the regulator has a utility function (or preference) over public wealth. This assumption is reasonable because the objective of the regulators is to regulate specific activities on behalf of the public. Notice that this assumption is different from the general assumption in economics that the utility function of an agent is the evaluation of his/her own wealth. In economics, individual decision makers are assumed to be self-interested. This assumption is not suitable for the case of regulatory decision making because public welfare is a primary objective. Assuming that the regulator only cares for his/her own benefit in regulation is equivalent to assuming that no regulator can be component.

Suppose an activity may lead to several possible outcomes and each outcome can be expressed as a monetary value. Assume the decision maker has a complete, reflexive, transitive, and continuous evaluation over these monetary outcomes, or in other words, he/she possesses a von Neumann-Morgenstern utility function. Let $x$ be an outcome and let $X$ be the set of possible outcomes. Let $p$ be a simple probability measure on $X$, thus $p=\left(p\left(x_{1}\right), p\left(x_{2}\right), \cdots, p\left(x_{n}\right)\right)$ where $p\left(x_{i}\right)$ are probabilities of outcome $x_{i} \in X$ $(i=1, \cdots, n)$ occurring. Note that there are finite elements $x \in X$ for which $p(x)>0$, and that $p\left(x_{i}\right) \geq 0$ for all $i=1, \cdots, n$ and $\sum_{i=1}^{n} p\left(x_{i}\right)=1$. The expected utility over the set of outcomes $X$ is expressed as,

$$
U(X)=\sum_{i=1}^{n} u\left(x_{i}\right) p\left(x_{i}\right)
$$

where $u(\cdot)$ is the von Neumann Morgenstern utility function. 
Let $\geq_{h}$ be a binary relation over $U$ so that $X \geq_{h} Y \Leftrightarrow U(X) \geq U(Y)$, which means that $X$ is preferred to, or equivalent to, $Y$ if and only if $U(X) \geq U(Y)$. Similarly, we have $X>{ }_{h} Y \Leftrightarrow U(X)>U(Y)$ and $X \sim Y \Leftrightarrow U(X)=U(Y)$. In this way, individuals can build a set of preferences over several alternatives.

Consider a scenario of regulatory decision making under risk (disposal of nuclear wastes, for example) where the risk is the possible realisation of environmental hazard. Suppose that the hazard may lead to a loss of wealth $w_{N}-w_{A}$ (measured by a monetary value), where $w_{N}$ denotes the original wealth and $w_{A}$ the reduced wealth if the hazard has occurred. In order to keep the risk within the acceptable range, an amount of money $C$ is going to be invested. The objective of regulatory decision making is to find the optimal amount of investment that maximizes the public good.

Let $\gamma$ denote the possibility (or risk) of the occurrence of an accident. We assume the existence of a state-independent utility function of the regulator $u(w)$ defined over payoffs, thus:

$$
U(\gamma, C)=\gamma u\left(w_{A}-C\right)+(1-\gamma) u\left(w_{N}-C\right)
$$

Notice that $U(\gamma, C)$ represents the expected utility of the regulator over public wealth and that $\gamma$ is a function of $C$ in the above equation.

The regulator's objective is to find the optimal amount of expenditure given $w_{A}$ and $w_{N}$. Thus the optimization problem is:

$$
\max U(\gamma, C)=\gamma u\left(w_{A}-C\right)+(1-\gamma) u\left(w_{N}-C\right)
$$

which yields the first order condition:

$$
\partial U(\gamma, C) / \partial C=\gamma^{\prime} u\left(w_{A}-C\right)+\gamma u^{\prime}\left(w_{A}-C\right)-\gamma^{\prime} u\left(w_{N}-C\right)+(1-\gamma) u^{\prime}\left(w_{N}-C\right)=0
$$


or, rearranging:

$$
\gamma^{\prime}\left(u\left(w_{N}-C\right)-u\left(w_{A}-C\right)\right)=\gamma u^{\prime}\left(w_{A}-C\right)+(1-\gamma) u^{\prime}\left(w_{N}-C\right)
$$

Let's first consider the case that the regulator is risk-neutral, that is, the utility function $u(w)$ is linear over $w \cdot u^{\prime}(w)$ is then a constant and, without loss of generality, suppose that $u^{\prime}(w)=k$. Notice that there are $u^{\prime}\left(w_{A}-C\right)=u^{\prime}\left(w_{N}-C\right)=k \quad$ and $u\left(w_{N}-C\right)-u\left(w_{A}-C\right)=k\left(w_{N}-w_{A}\right)$, we have (4) directly from (3).

$$
\gamma^{\prime}=1 /\left(w_{N}-w_{A}\right)
$$

Equation (4) gives the condition of optimal expenditure against risk. Fig.2 shows how the optimal expenditure $C_{o p t}$ can be computed. The X-Y axes as shown in Fig.2 denote the expenditure $C$ and the possibility of risk $\gamma$ respectively. The line $F$ which satisfies (4) intersects the curve $\gamma(C)$ at a point $A$. Point $A$ denotes the optimal solution of benefit-expenditure tradeoff that maximizes the expected utility. The expenditure is $C_{o p t}$ when the risk is reduced to the level of $\gamma_{o p t}$, which means that the ratio of marginal reduction of the risk to the expenditure is maximized, or in other words, the risk is reduced to the degree so that a further reduction needs much more expenditure and is therefore not economical.

The optimal expenditure $\gamma_{o p t}$ depends crucially on the assumption of linearity property of the utility function. Suppose, however, the regulator is not risk-neutral, optimal expenditure will deviate from $\gamma_{o p t}$. When the regulator is risk-averse, he would rather invest more money to reduce the risk involved, and there should be

$$
\gamma^{\prime}<1 /\left(w_{n}-w_{A}\right)
$$


Consider the line $G$ (as shown in Fig.2) that satisfies (5), for example, a risk-averse agent's decision may be point $B$, with which the expenditure increases $\left(C_{B}>C_{O p t}\right)$ and the possibility of an accident decreases $\left(\gamma_{B}<\gamma_{O p t}\right)$ compared to the risk-neutral case. The more risk-averse an agent is, the more expenditure he/she would like to invest in order to reduce the risk.

If the agent is risk-prone, on the other hand, he would prefer an alternative with less expenditure and higher risk to the alternative with $\gamma_{O p t}$ and $C_{O p t}$.

This benefit-expenditure analysis is not sufficient for a regulator to make their final decision because it provides only one of the criteria that should be taken into consideration. Notice that the alternative with $C_{O p t}$ is optimal only if $\gamma_{o p t}$ is an acceptable value of risk (as shown in Fig. 3(a)). If an alternative may cause an intolerable level of risk, it is unacceptable no matter how much benefit it will create.

Arrow and Lind [24] have indicated that a regulator should behave in a risk- neutral fashion. Under the assumption of risk-neutral, the regulatory decisions could be transparent and consistent among the stakeholders.

\section{AN EXAMPLE OF APPLICATION}

The city of Istanbul, Turkey is within an area with the possibility that strong earthquakes will occur in the near future due to the underlying geography. Since 1999 earthquakes near Istanbul have caused more than 18,000 deaths. As a consequence, there has been increasing awareness of trying to reduce the risk of loss (especially loss of human life) when a damaging earthquake happens. 
Smyth et al. [25, 26] introduced a cost-benefit analysis of seismic retrofitting measures of a representative apartment building in Istanbul, in which three alternative options of retrofitting the building were given in order to reinforce its structure. These alternatives denote three levels of retrofit: braced, partial shear wall, and full shear wall solutions. The probabilities of the building collapse and mitigation cost for these retrofit options together with the option of no retrofit are listed in Table 1.

The loss in damaging earthquakes is determined by evaluating the expected damage to the property and the reduction in fatalities from earthquakes. The direct economic loss due to building damage or collapse is estimated to be $\$ 250,000$. Let $N_{L}$ and $V$ denote the expected number of fatalities and the expected cost of a human life respectively. The cost of fatalities can then be expressed as $N_{L} V$.

We now apply the proposed approach to this issue in order to evaluate and compare mitigation alternatives. The objective of choosing between different alternatives is to prevent the building from collapsing in earthquakes so as to reduce the expected number of fatalities. It should be pointed out that the objective of this example is to demonstrate the usage and potential of the proposed approach, rather than to focus on determining precise values of this specific instance. Instead of evaluating the expected number of fatalities and cost of human lives, $N_{L}$ and $V$, we consider the cases of different values of $N_{L}$ and $V$ so that a link between evaluating mitigation alternatives and the expected cost of fatalities can be established. If the social discount rate is taken into consideration, the net present value of the cost of fatalities will be significantly lower than $N_{L} V$. When the social discount rate is set to be $5 \%$, for example, the net present value of $\$ 100$ is approximately $\$ 29.53$ if the payment will stochastically occur in 50 years. For a detailed 
discussion about social discount rate and the evaluation of human lives, see Boardman [17] and Viscusi [27].

Let's first assume $V=\$ 500,000$, and discount rate is zero, and consider the cases of $N_{L}=0,2,5,10$. The total loss of wealth can be expressed as $w_{N}-w_{A}=N_{L} V+\$ 250,000$. The computation of the optimal alternative is shown in Figure 4. Each alternative $\mathrm{A}_{i}$ $(i=1,2,3,4)$ can be depicted by a point in $\mathrm{X}-\mathrm{Y}$ coordinates when $\mathrm{X}$ and $\mathrm{Y}$ axis denote cost of alternative and the possibility of collapse respectively. For each value of $N_{L}$, we can find a line that satisfies (4) and intersects an alternative and that all other alternatives lie on the left side of this line. Then, the alternative that intersects with the line is the optimal solution. Consider the case of $N_{L}=0$, for example. We have $\gamma^{\prime}=\frac{1}{250,000}$ according to (4). If we draw a line that satisfies $\frac{d Y}{d X}=\frac{1}{250,000}$ through A1, all of A2, A3 and A4 lie on the left side of this line. Thus, A1 is the optimal alternative for $N_{L}=0$, which means that remaining status quo is the best choice if there will be no fatalities in future earthquakes.

In this way, the optimal alternative for any value of $N_{L}$ can be computed. The results are shown in Figure 5. The optimal alternative is A1 for $N_{L}=0,1 ; \mathrm{A} 2$ for $N_{L}=2$; and A3 for $N_{L} \geq 3$.

If we use the cost of fatalities $N_{L} V$ as a variable, the optimal alternative is actually a function of $N_{L} V$. Let $A_{o p t}$ denotes the optimal alternative, we have

$$
A_{\text {opt }}= \begin{cases}A_{1} & \text { if } N_{L} V \leq \$ 616,666 \\ A_{2} & \text { if } \$ 616,666<N_{L} V \leq \$ 1,083,333 \\ A_{3} & \text { if } \$ 1,083,333<N_{L} V\end{cases}
$$


If the social discount rate is set to be $5 \%$, for example, the optimal alternative will be,

$$
A_{\text {opt }}= \begin{cases}A_{1} & \text { if } N_{L} V \leq \$ 2,088,249 \\ A_{2} & \text { if } \$ 2,088,249<N_{L} V \leq \$ 3,668,550 \\ A_{3} & \text { if } \$ 3,668,550<N_{L} V\end{cases}
$$

This can be expressed as Figure 6. The optimal retrofit alternative can be determined for any value of social discount rate and $N_{L} V$ in this way.

In order to make a comparison between the outcomes of Smyth et al. [26] and ours, we introduce the factor of time horizon. Briefly, time horizon $T_{N}$ indicates the time period that the apartment building will last. Although the building may be expected to last for 50 years if the area does not experience a severe earthquake, there may be an interest in evaluating the attractiveness of the investment using shorter time horizons. Other settings include social discount rate $d=0.1$, value of the building $\$ 250,000$, and the cost of fatalities $N_{L} V=\$ 10$ million.

The results of optimal alternatives over different time horizons are shown in Fig.7. By comparing Fig. 7 with Table 2, it shows that our results are consistent with that of Smyth et al. [26] in most cases except the case when time horizon is equal to five years. The advantage of our approach is that the alternatives are compared with each other by means of their efficiencies in the reduction of the risks.

\section{CONCLUSIONS AND FUTURE RESEARCH}

Marginal analysis based on the philosophy of utilitarianism is widely applied to achieve economic efficiency. Utilitarian philosophy suggests that decisions be made with the ultimate objective of maximizing societal welfare. In this study, we propose a 
'marginal' approach for regulatory decision making under risk. This approach offers an analysis of the best alternative that maximizes the ratio of marginal reduction of the risk to the expenditure, which means that the reduction of the risk can be taken into consideration within the context of CBA directly.

While this study makes a preliminary effort to link the results of economic analysis with the framework of ALARP, it should be remembered that it has been conducted using some assumptions, for example the assumptions of the regulator's utility function over public wealth and the regulator is payoff-maximized. These assumptions may be debatable outside the field of economics.

Regulatory decision making is generally a process that many stakeholders are involved. Although the regulator's views can be decisive when there is a disagreement on the issue of regulation, stakeholders' opinions are never negligible, especially when seriously consequence is possible. Actually, there are always discussions and negotiations between the regulator and other stakeholders that may include the operators, regulation advisors, scientists, and government policy maker, etc before a regulatory decision has been made. Group decision making is a complex problem in that many individual, group and contextual factors may take effect. If the interactions between stakeholders of regulation are taken into consideration, the regulatory decision making turns out to be the negotiation between stakeholders.

The costs and benefits of risk reduction are rarely distributed equally across all communities exposed to hazards. Most cost benefit analyses concentrates on net costs and net benefits so that perspectives of different stakeholders could not been taken into account. Theoretically, this problem of equity is to some extent solvable by means of 
negotiation. In our future research regulatory decision making will be investigated as a process of group decisions in which negotiation between stakeholders, brokering of scientific knowledge, influence of power hierarchy is considered.

\section{ACKNOWLEDGEMENTS}

This research was supported by EPSRC (Engineering and Physical Sciences Research Council) grant (Ref: EP/E017975/1). G. Davies is supported by an EPSRC studentship at Cranfield University.

\section{REFERENCES}

[1] HSE. Reducing risks — protecting people: HSE's decision making process, HMSO, Norwich. Available at www.hse.gov.uk/risk/theory/r2p2.pdf, 2001.

[2] Bent F, Mette H, and Søren B. How (In)accurate Are Demand Forecasts in Public Works Projects? The Case of Transportation. Journal of the American Planning Association, 2005;71(2): 131-146.

[3] Sugden R. Developing a Consistent Cost-benefit Framework for Multi-Modal Transport Appraisal, Economics Research Centre, University of East Anglia, 1999.

[4] McIntosh E, Donaldson C, Ryan M. Recent advances in the methods of cost-benefit analysis in healthcare. Matching the art to the science. Pharmaco Economics, 1999;15(4): 357-67.

[5] Folland S, Goodman A, and Stano M. The Economics of Heath and Health Care. Fifth ed. Pearson Prentice Hall: New Jersey, 2007.

[6] Tengs T, Miriam A, Joseph P, Dana S, Joanna S, Milton W, John G. Five-Hundred Life-Saving Interventions and Their Cost-Effectiveness. Risk Analysis, 1995;15(3): 369-390.

[7] Morgenstern, R. Economic Analyses at EPA: Assessing Regulatory Impact. Washington, D.C.: Resources for the Future, 1997.

[8] Carson R, Mitchell R, Hanemann M, Kopp R, Presser S, and Ruud P. Contingent Valuation and Lost Passive Use: Damages from the Exxon Valdez Oil Spill, Environmental and Resource Economics, 2003;25: 257-286.

[9] Sunstein C. Cost-Benefit Analysis and the Environment, University of Chicago Law \& Economics, Olin Working Paper 2007; No. 227. 
[10] Kishimoto A, Oka T, Yoshida K and Nakanishi J. Cost-Effectiveness of Reducing Dioxin Emission from Municipal Solid Waste Incinerators in Japan, Environmental Science and Technology, 2001;35: 2861-2866.

[11] Harris G and Olukoga T. A cost benefit analysis of an enhanced seat belt enforcement program in South Africa, Injury Prevention, 2005;11:102-105.

[12] Grossman P and Cassedy E. Cost-Benefit Analysis of Nuclear Waste Disposal: Accounting for Safeguards, Science, Technology, \& Human Values, 1985;10(4):47-54.

[13] French S. Decision theory: an introduction to the mathematics of rationality, Chichester: Ellis Horwood, 1986.

[14] Pape R. Developments in the tolerability of risk (TOR) and the application of ALARA, Nuclear Energy, 1997;36: 457-63.

[15] Belzer R. Discounting across generations: necessary not suspect, Risk Analysis, 2000;20: 779-92.

[16] Shrader-Frechette K. Risk, ethics and discounting future generations, in Mosleh A and Bari R (eds) PSAM4 Proceedings, New York: Springer, 1998.

[17] Boardman A, Greenberg D, Vining A, Weimer D. Cost-Benefit Analysis: Concepts and Practice (2nd Edition). Upper Saddle River, NJ: Prentice Hall, 2001.

[18] Adams J. Risk, London: UCL Press, 1995.

[19] Arrow K, Maureen C, George E, Robert H, Lester L, Roger N, Paul P, Milton R, Richard S, Kerry S, and Robert $\mathrm{S}$. Is there a role for benefit-cost analysis in environmental, health, and safety regulation?, Science, 1996;272:221-222.

[20] Friedrich von Wieser, The Nature and Essence of Theoretical Economics, 1884, 128-129.

[21] James Huston McCulloch, The Austrian Theory of the Marginal Use and of Ordinal Marginal Utility, Zeitschrift für Nationalökonomie, 1977; 37: \#3\&4.

[22] Melchers R. On the ALARP approach to risk management, Reliability Engineering \& System Safety, 2000;71(2): 201-208.

[23] Hughes S. Cost-effective application of the ALARP principle, Paper No.11 on Symposium of ESAS'05, 2005.

[24] Arrow K and Lind R. Uncertainty and the Evaluation of Public Investment. American Economic Review, 1970;60(3): 364-78.

[25] Smyth A, Deodatis G, Franco G, Kunreuther H, and Lus H. Benefit-Cost Analysis for Mitigating Seismic Losses: Probabilistic Evaluation of Retrofit Measures for Residential Buildings in Turkey, in International Conference on Applications of Statistics and Probability in Civil Engineering, ICASP, San Francisco, 2003.

[26] Smyth A, Altay G, Deodatis G, Erdik M, Franco G, Gulkan P, Kunreuther H, Lus H, Mete E, Seeber N, and Yuzugullu O. Probabilistic Benefit-Cost Analysis for Earthquake Damage Mitigation: Evaluating Measures for Apartment Houses in Turkey, Earthquake Spectra, 2004;20(1): 171-203.

[27] Viscusi K. The Value of Risks to Life and Health. Journal of Economic Literature, 1993;31:1912-46. 
[28] French S, Bedford T, and Atherton E. Supporting ALARP decision making by cost benefit analysis and multiattribute utility theory, Journal of Risk Research, 2005;8(3): 207-233. 


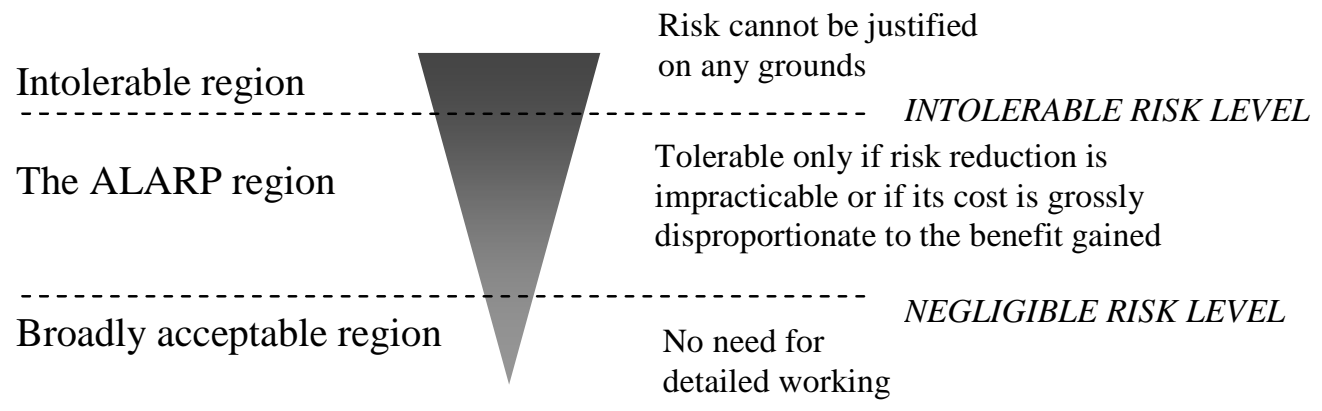

Figure 1 Optimizing risks and benefits. The width of the triangle represents the possibility of risk involves.

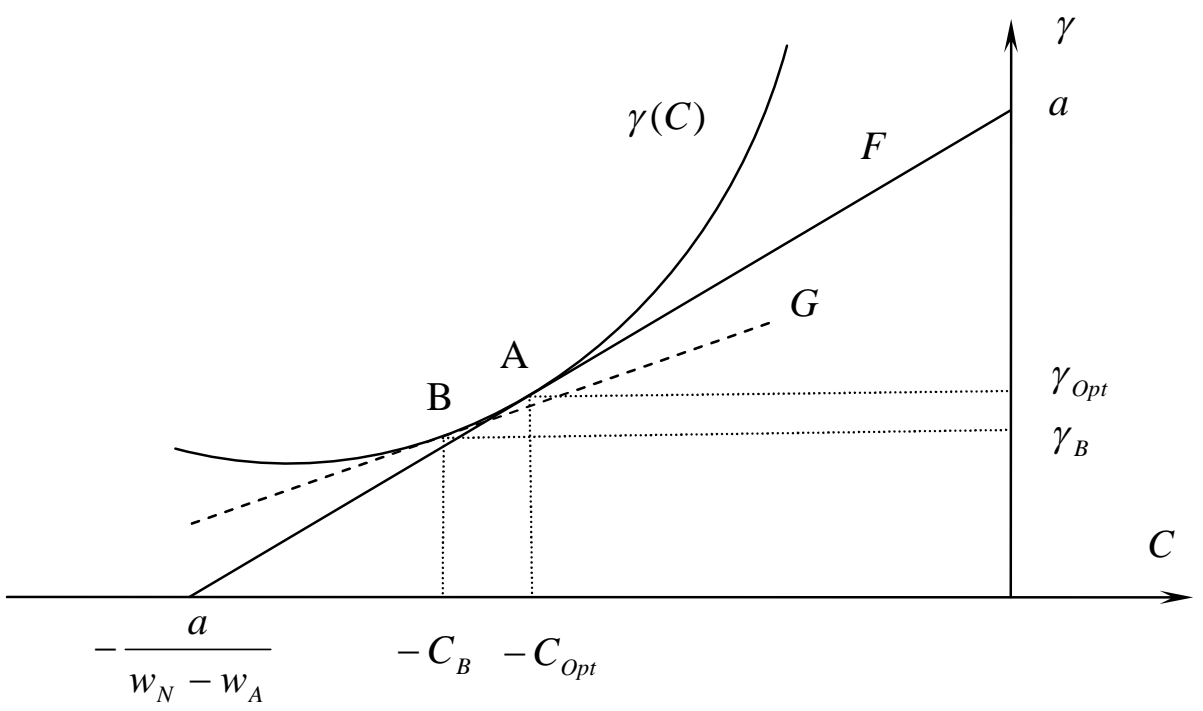

Figure 2 Optimal expenditure $C_{o p t}$ is the point where line $F$ interacts with the curve $\gamma(C)$. With $C_{\text {opt }}$, the utility is maximized and the risk is reduced most economically. 


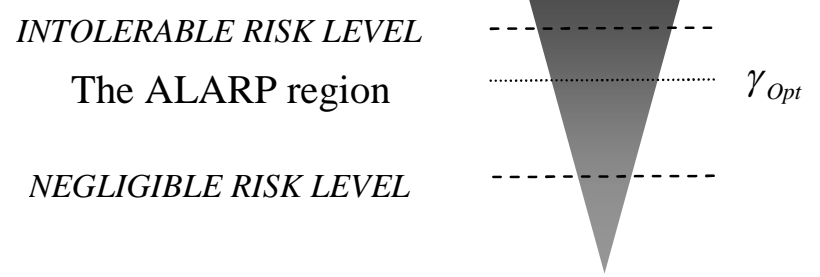

(a)

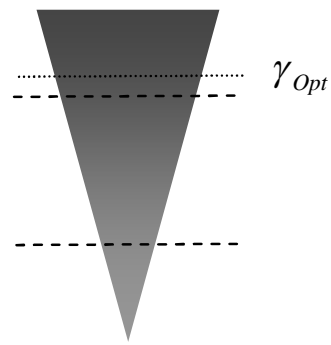

(b)

Figure 3 (a) $C_{O p t}$ is acceptable only if $\gamma_{O p t}$ is smaller than the unacceptable risk level (most possibly within the ALARP region) (b) If $\gamma_{o p t}$ is within the unacceptable risk region, an alternative with expenditure $C\left(C>C_{O p t}\right)$ which will lead to an acceptable value of risk is preferred.

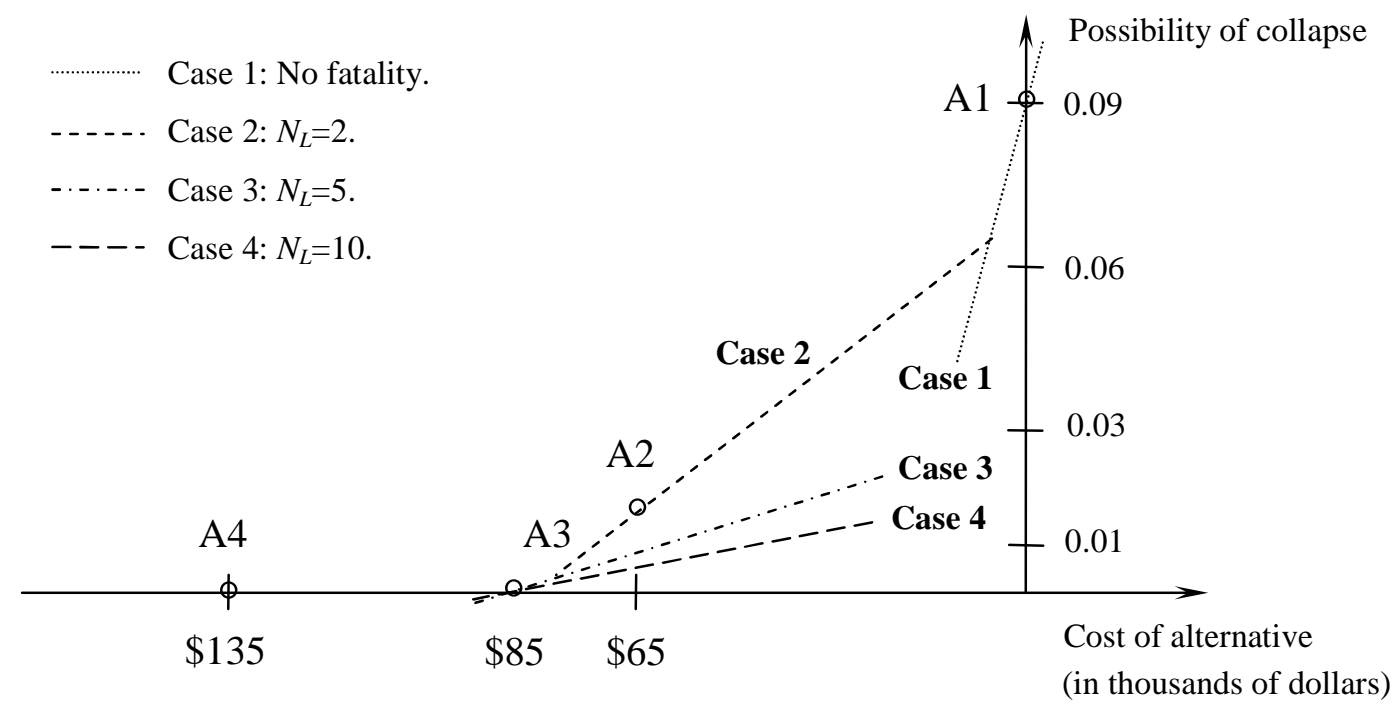

Figure 4 Computation of the optimal alternative. Alternative $\mathrm{A1}$ is optimal in case 1; $\mathrm{A2}$ is optimal in case 2; A3 is optimal in case 3 and 4. 
Optimal Alternative

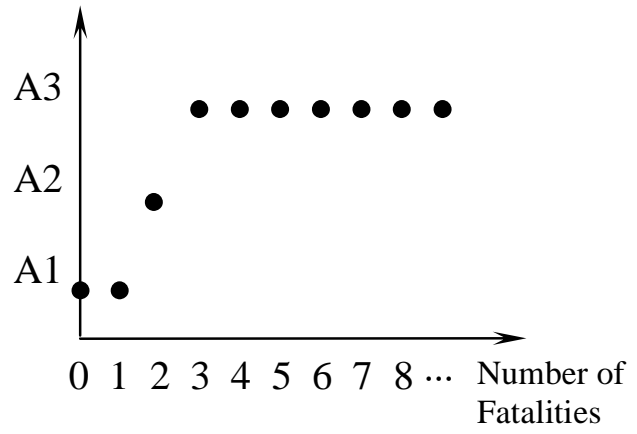

Figure 5 Optimal retrofit alternative as one varies $N_{L}$, given $V=\$ 500,000$.

Optimal Alternative

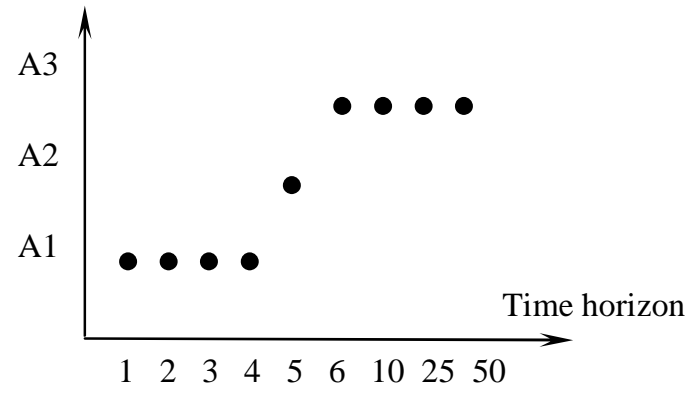

Figure 7 Optimal Alternatives.
Optimal Alternative

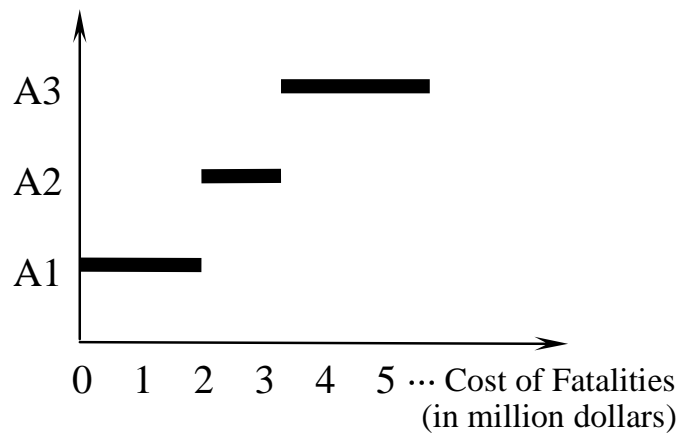

Figure 6 Optimal retrofit alternative as one varies $N_{L} V$, given discount rate $5 \%$. 
Table 1 Alternative options of retrofitting an apartment building (Smyth et al. (2003, 2004)).

\begin{tabular}{l|c|c}
\hline Alternative & Probability of Collapse $^{*}$ & Mitigation Cost $^{*}$ \\
\hline A1 Status Quo (original) & 0.09 & $\$ 0$ \\
A2 Braced & 0.015 & $\$ 65,000$ \\
A3 Partial (shear wall) & $\sim 0$ & $\$ 85,000$ \\
A4 Full (shear wall) & $\sim 0$ & $\$ 135,000$ \\
\hline
\end{tabular}

* Note that values in this column denote the probabilities of the building collapse during 50 years, not annual probabilities of collapse.

** Compared with A3, A4 is obviously unnecessary in reducing the risk of collapse. This is because we are considering only the extreme situation in which human lives are in danger. If the economic losses from serious damage (not as serious as collapse) of the building are taken into consideration, A4 may be attractive because it makes the building much more solid. We keep this option here in order to be consistent with the original literature. 
TABLE 2 Expected Net Present Value (in thousands of dollars) (Smyth et al. (2004)).

\begin{tabular}{cccc} 
Time Horizon & \multicolumn{1}{c}{$\boldsymbol{A 2}$} & \multicolumn{1}{c}{$\boldsymbol{A 3}$} & \multicolumn{1}{c}{$\boldsymbol{A 4}$} \\
$\mathbf{1}$ & $-\$ 49.3$ & $-\$ 58.8$ & $-\$ 113.4$ \\
$\mathbf{2}$ & $-\$ 35.8$ & $-\$ 40.7$ & $-\$ 94.8$ \\
$\mathbf{3}$ & $-\$ 24.3$ & $-\$ 25.1$ & $-\$ 78.9$ \\
$\mathbf{4}$ & $-\$ 14.3$ & $-\$ 11.7$ & $-\$ 65.2$ \\
$\mathbf{5}$ & $-\$ 5.8$ & $-\$ 0.3$ & $-\$ 53.5$ \\
$\mathbf{6}$ & $\$ 1.4$ & $\$ 9.5$ & $-\$ 43.5$ \\
$\mathbf{1 0}$ & $\$ 21.6$ & $\$ 36.7$ & $-\$ 15.8$ \\
$\mathbf{2 5}$ & $\$ 42.9$ & $\$ 65.4$ & $\$ 13.6$ \\
$\mathbf{5 0}$ & $\$ 45.2$ & $\$ 68.5$ & $\$ 16.8$
\end{tabular}

